\title{
Anisotropy in nanocellular polymers promoted by the addition of needle-like sepiolites
}

\author{
Victoria Bernardo, ${ }^{*} \odot$ Judith Martin-de Leon \\ and Miguel Angel Rodriguez-Perez
}

\begin{abstract}
This work presents a new strategy for obtaining nanocellular materials with high anisotropy ratios by means of the addition of needle-like nanoparticles. Nanocellular polymers are of great interest due to their outstanding properties, whereas anisotropic structures allow the realization of improved thermal and mechanical properties in certain directions. Nanocomposites based on poly(methyl methacrylate) (PMMA) with nanometric sepiolites are generated by extrusion. From the extruded filaments, cellular materials are produced using a two-step gas dissolution foaming method. The effect of adding various types and contents of sepiolites is investigated. As a result of the extrusion process, the needle-like sepiolites are aligned in the machine direction in the solid nanocomposites. Regarding the cellular materials, the addition of sepiolites allows one to obtain anisotropic nanocellular polymers with cell sizes of 150 to $420 \mathrm{~nm}$ and cell nucleation densities of $10^{13}-10^{14}$ nuclei cm $^{-3}$ and presenting anisotropy ratios ranging from 1.38 to 2.15, the extrusion direction being the direction of the anisotropy. To explain the appearance of anisotropy, a mechanism based on cell coalescence is proposed and discussed. In addition, it is shown that it is possible to control the anisotropy ratio of the PMMA/sepiolite nanocellular polymers by changing the amount of well-dispersed sepiolites in the solid nanocomposites.
\end{abstract}

(c) 2019 Society of Chemical Industry

Supporting information may be found in the online version of this article.

Keywords: nanocellular polymer; PMMA; gas dissolution foaming; nanoparticles; anisotropy

\section{INTRODUCTION}

Cellular polymers present a very interesting combination of properties that have promoted their widespread use in almost every industrial sector, such as the automotive and aeronautical industries, renewable energies, construction, biotechnology, cushioning and packaging. ${ }^{1}$ The cellular polymer market is, therefore, a relevant economic sector, and it is estimated to reach $\$ 126.08$ billion by 2022 , at an annual growth rate of $5.86 \% .^{2}$ Due to the importance of cellular polymers, there is much research focusing on producing these materials with enhanced and novel properties. In particular, one of the most promising research areas in this field is the study of nanocellular polymers, that is, cellular polymers with cell sizes in the range of tens to hundreds of nanometres. ${ }^{3-5}$

The reduction of cell size to the nanometric range is known to have an important effect on the performance of cellular materials. ${ }^{6,7}$ For instance, it has been proved that nanocellular polymers exhibit the so-called Knudsen effect, which results in a marked decrease in the conductivity of the gas phase in these materials. ${ }^{8-12}$ Also, it has been recently shown that nanocellular materials can be semi-transparent, ${ }^{13,14}$ among other effects. ${ }^{6,15-18}$ Some of the most interesting properties of these materials, such as the very low thermal conductivity or the transparent behaviour, depend strongly on the density of the cellular material and require low-density materials to reach their maximum potential. However, it is well established that the reduction of the density in cellular polymers implies a significant reduction of the mechanical response, with normally a square dependency with density. ${ }^{19}$
One strategy to avoid this loss of properties is the production of anisotropic cellular materials with improved mechanical performance in the direction in which cells are oriented. In addition to this, anisotropy can also be used to modify thermal conductivity because both conduction through the solid phase and radiation strongly depend on anisotropy.

Anisotropic cellular structures are characterized by cells elongated in one direction. The cell anisotropy can be quantified through the anisotropy ratio, which is defined as the ratio between the maximum and the minimum length of the cell. ${ }^{20}$ It has been extensively shown that the anisotropy of the cellular structure has significant effects on the mechanical properties of cellular polymers. Huber and Gibson ${ }^{20}$ proposed a theoretical model to predict the improvement in properties such as Young's modulus, plastic collapse or fracture toughness, this model being validated using polyurethane cellular materials. Moreover, for example, Andersons et al. ${ }^{21}$ showed that the stiffness of low-density closed-cell cellular polyisocyanurate increased by a factor of 3 in the anisotropy direction for anisotropy ratios of around 1.5. The thermal conductivity of cellular polymers is also a function of cells anisotropy;

\footnotetext{
Correspondence to: V Bernardo, Cellular Materials Laboratory (CellMat), Condensed Matter Physics Department, Faculty of Science, University of Valladoli, Valladolid, Spain.E-mail:vbernardo@fmc.uva.es

Cellular Materials Laboratory (CellMat), Condensed Matter Physics Department, Faculty of Science, University of Valladoli, Valladolid, Spain
} 
thermal conductivity is reduced when the cells are elongated in a direction perpendicular to that of the heat flow. ${ }^{22-24}$ The conductivity due to the solid phase is reduced due to the higher solid-phase tortuosity of the cellular structure in the heat flow direction (when cells are elongated in the direction perpendicular to that of the heat flow). In addition, the number of cell walls to scatter radiation is also increased in the heat flow direction, increasing the extinction coefficient and reducing the thermal conductivity.

Cellular polymers usually present anisotropy ratios of around 1.3 or smaller, ${ }^{20}$ so specific production routes must be designed to obtain materials with higher anisotropy ratios. Most of the strategies used to date to produce anisotropic cellular structures rely on the selective growth of the cells in one direction. For instance, the freeze-casting technique, which is well known to be useful for producing anisotropic porous structures, ${ }^{25}$ was used successfully to produce porous poly(vinyl alcohol)/sepiolite nanocomposites with anisotropy ratios of 1.34 by Killeen and co-workers. ${ }^{26}$ The anisotropy observed was due to the growth of ice crystals in a mould and increased by the addition of fibrous sepiolites. In the work of Laguna-Gutierrez et al., ${ }^{27}$ cellular polypropylene with anisotropy ratios of around 3 was obtained via an improved compression moulding technique, that forces cell growth in one direction. Mould shape was used by Arora and co-workers ${ }^{28}$ to obtain polystyrene-based anisotropic cellular materials. Oliveira-Salmazo et al. ${ }^{29}$ used a different approach to control the anisotropy ratio (from 0.9 to 2.48 ) in natural rubber cellular samples by means of varying the dimensions of the solid precursors. In the work of Bernardo et al., ${ }^{30}$ cell anisotropy was also promoted by the mould shape, but controlled by the process parameters. This process allowed the realization of cellular high-density polyethylene with very high anisotropy ratios, ranging from 2.95 to 3.75 .

In the work reported here, a new strategy was developed to obtain anisotropic structures in nanocellular materials. Instead of inducing anisotropy via cellular growth, the anisotropy was obtained solely because of the addition of needle-like particles with a strong orientation in the solid material. Nanocomposites of poly(methyl methacrylate) (PMMA) with nanometric sepiolites were produced by extrusion and foamed using the gas dissolution foaming method. As a result of the alignment of the particles during the extrusion, the cells are elongated in the extrusion direction. The strategy used to achieve highly anisotropic cells is new, and also, as far as the authors know, this is the first time that anisotropic nanocellular polymers have been produced. These materials would have the potential to be very efficient thermal insulators in the direction perpendicular to that of the orientation of the cells and present significantly better mechanical performance in the anisotropy direction.

\section{EXPERIMENTAL}

\section{Materials}

PMMA (V825T; $M_{\mathrm{n}}=43 \mathrm{~kg} \mathrm{~mol}^{-1}, M_{\mathrm{w}}=83 \mathrm{~kg} \mathrm{~mol}^{-1}$ ) was kindly supplied by ALTUGLAS ${ }^{\circledR}$ International in the form of pellets with a density $(\rho)$ of $1.18 \mathrm{~g} \mathrm{~cm}^{-3}$ and a glass transition temperature of $114.5^{\circ} \mathrm{C}$ as measured using DSC.

Sepiolites were kindly provided by Tolsa SA (Spain). The chemical formulation of these particles corresponds to hydrated magnesium silicate (formula $\mathrm{Si}_{12} \mathrm{Mg}_{8} \mathrm{O}_{30}(\mathrm{OH})_{4}\left(\mathrm{OH}_{2}\right)_{4} \cdot 8 \mathrm{H}_{2} \mathrm{O}$ ). They present a needle-like morphology, with an average particle length ranging from 1 to $2 \mu \mathrm{m}$ and a diameter between 20 and $30 \mathrm{~nm}^{31,32}$
Table 1. Formulations used in this work

\begin{tabular}{|llc|} 
Material ID & \multicolumn{1}{c}{ Filler type } & $\begin{array}{c}\text { Filler } \\
\text { content } \\
\text { (wt } \%)\end{array}$ \\
\hline PMMA & None & 0 \\
$1.5 \%-Q A S$ & Quaternary ammonium salt (QAS) & 1.5 \\
$1.5 \%-$-LQAS & $\begin{array}{c}\text { Sepiolite modified with a low amount } \\
\text { of QAS (S-LQAS) }\end{array}$ & 1.5 \\
$1.5 \%-$-HQAS & $\begin{array}{c}\text { Sepiolite modified with a high amount } \\
\text { of QAS (S-HQAS) }\end{array}$ & 1.5 \\
$3 \%-$-HQAS & $\begin{array}{c}\text { Sepiolite modified with a high amount } \\
\text { of QAS (S-HQAS) }\end{array}$ & 3 \\
$10 \%-S-H Q A S$ & $\begin{array}{c}\text { Sepiolite modified with a high amount } \\
\text { of QAS (S-HQAS) }\end{array}$ & 10 \\
\hline
\end{tabular}

The sepiolites used in this work have been modified with a quaternary ammonium salt (QAS). Two types of sepiolites with different grade of modification were used: S-LQAS, sepiolite modified with a low amount of QAS (9.5 wt\%); and S-HQAS, sepiolite modified with a higher amount of QAS $(20.5 \mathrm{wt} \%$, more than twice that of the other sepiolite). The amount of QAS in each sepiolite was determined by performing TGA of the modified sepiolites, the raw salt and the same sepiolites without surface modification. The process of obtaining and modifying these particles is detailed elsewhere. ${ }^{33,34}$ The raw QAS used for the modification was also used in this work as a filler to evaluate its effect on the cellular materials.

Medical-grade carbon dioxide ( $99.9 \%$ purity) was used as the blowing agent for the gas dissolution foaming experiments.

\section{Solid blend production}

A twin-screw extruder, model COLLIN TEACH-LINE ZK 25T, with $L / D$ equal to 24 and screw diameter equal to $25 \mathrm{~mm}$ was used to produce the PMMA/sepiolite nanocomposites. The materials produced in this work are summarized in Table 1. PMMA was dried in a vacuum oven at $50^{\circ} \mathrm{C}$ for at least $12 \mathrm{~h}$ before blending, whereas sepiolites were dried at higher temperature $\left(80^{\circ} \mathrm{C}\right)$ also under vacuum. The temperature profile set on the extruder was from 160 to $200^{\circ} \mathrm{C}$ in the die, increasing at intervals equal to $10^{\circ} \mathrm{C}$. The screw speed was equal to $40 \mathrm{rpm}$. The produced blends were cooled in a water bath and pelletized. After drying the pellets, each blend was extruded again using the same processing conditions to afford a homogeneous dispersion of the particles. During the second extrusion, the extruded filament (with a thickness of around 3-4 mm) was not pelletized but set aside for the foaming experiments. Cylindrical samples of $30 \mathrm{~mm}$ in length and $3-4 \mathrm{~mm}$ in diameter were cut from the extruded filaments for the foaming experiments.

Note that pure PMMA was processed under the same conditions for comparison purposes. Also, a material with the QAS (but without sepiolites) was produced to analyse its effect on the foaming behaviour. Rheology measurements, MFI and DSC were used to validate that the extrusion process did not affect significantly the morphology and properties of PMMA ${ }^{27,35,36}$ (see supporting information for these results).

\section{Gas dissolution foaming experiments}

Foaming experiments were performed using a high-pressure vessel (model PARR 4681) provided by Parr Instrument Company 
(a)

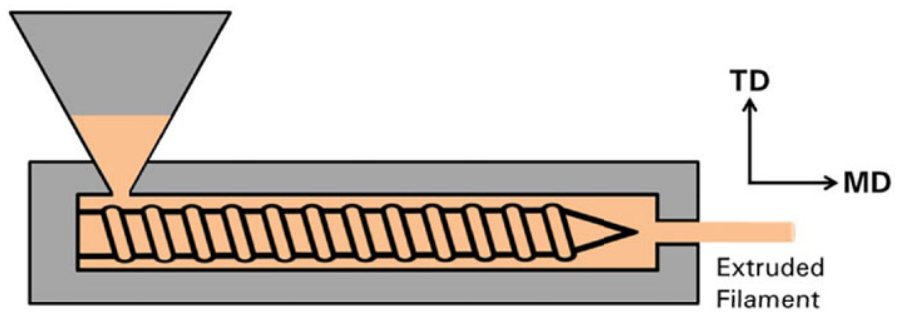

(b)

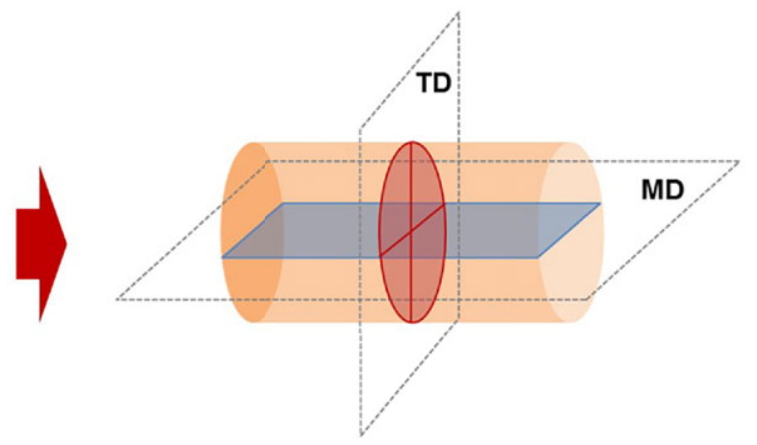

Figure 1. (a) Scheme of extrusion process and (b) planes analysed to characterize solid materials and foamed samples.

with a capacity of $1 \mathrm{~L}$, able to operate at maximum temperature and pressure of $350^{\circ} \mathrm{C}$ and $41 \mathrm{MPa}$, respectively. Pressure was controlled with a pressure pump controller (model SFT-10) provided by Supercritical Fluid Technologies Inc. A clamp heater of $1200 \mathrm{~W}$ and a CAL 3300 temperature controller allowed the control of the temperature of the vessel. Foaming experiments were conducted using a two-step foaming process. ${ }^{37}$ First, samples were put into the pressure vessel at a constant $\mathrm{CO}_{2}$ pressure of $10 \mathrm{MPa}$ and at a temperature of $25^{\circ} \mathrm{C}$ for the saturation stage during $20 \mathrm{~h}$, enough to achieve saturation of $\mathrm{CO}_{2}$ in the PMMA samples. ${ }^{38}$ Then, the pressure was abruptly released at a pressure drop rate of $15 \mathrm{MPa} \mathrm{s}^{-1}$ at the first moments of the pressure drop. Finally, the samples were removed from the pressure vessel and immediately after (around $2.5 \mathrm{~min}$ ) introduced into a thermal bath with water at $80^{\circ} \mathrm{C}$ for $1 \mathrm{~min}$ for the foaming step.

\section{Characterization \\ Density}

The density of the solid materials was measured with a gas pycnometer (AccuPyc II 1340, Micromeritics). The density of the cellular materials was determined with the water displacement method based on the Archimedes principle using a density determination kit for an AT261 Mettler-Toledo balance. The solid skin of the cylindrical foamed samples was removed with a polisher (LaboPOl2-LaboForce3, Struers) by polishing off more than $500 \mu \mathrm{m}$ of the surface before measuring the densities. Relative density $\left(\rho_{\mathrm{r}}\right)$ is defined as the ratio between the cellular material density $(\rho)$ and the density of the solid materials with the same composition $\left(\rho_{\mathrm{s}}\right)$.

\section{Morphology of solids and cellular structure}

Samples were cooled in liquid nitrogen and then fractured for microscopic visualization and coated with gold using a sputter coater (SCD 005, Balzers Union). The morphology of the samples was analysed using an environmental SEM instrument (QUANTA 200 FEG). Both solid and cellular materials were fractured in two perpendicular directions to visualize two planes: the plane parallel to the extrusion direction (MD, machine direction); and the plane perpendicular to the extrusion line (TD, transverse direction) (Fig. 1).

For the solid nanocomposites, the density of nanoparticles was determined by counting the number of particles $\left(n_{\mathrm{p}}\right)$ in a given area $\left(A_{\mathrm{p}}\right)$. Taking into account that the surfaces analysed come from a fracture, we assumed that we were only observing half of the particles that were in this area $A_{p}$ (the other half would be in the other fracture surface). Then, the density of nanoparticles $\left(N_{p}\right)$ is calculated according to Eqn (1), where the factor of 2 accounts for the miscount of particles in the analysis:

$$
N_{\mathrm{p}}=\left[\frac{2 n_{\mathrm{p}}}{A_{\mathrm{p}}}\right]^{3 / 2}
$$

The cellular materials of this work with sepiolites present a bimodal structure with micrometric and nanometric cells. In a bimodal cellular structure, the micrometric cells, though smaller in number, typically occupy a significant volume of the sample. Then, to quantify the observed bimodality, the relative volume occupied by the population of nanometric cells, $V_{\text {nano, }}$ is measured: ${ }^{38}$

$$
V_{\text {nano }}=100 \frac{A_{\mathrm{t}}-A_{\mathrm{m}}}{A_{\mathrm{t}}}
$$

where $A_{\mathrm{m}}$ is the observed area occupied by the micrometric cells (cell sizes greater than $1 \mu \mathrm{m}$ ) in the SEM images and $A_{\mathrm{t}}$ the total area of the image. The resulting two-dimensional area ratio is equivalent to the three-dimensional volume ratio given that the surfaces analysed were uniform and random, according to the Delesse principle in stereology. ${ }^{39,40}$ In the microcellular materials without a nanocellular structure (that is, those without sepiolites), this parameter was not calculated and considered as zero.

Software based on ImageJ/FIJI was used to characterize the cellular structure of the foamed samples. ${ }^{41}$ Cell density $\left(N_{\mathrm{v}}\right)$ and cell nucleation density $\left(N_{0}\right)$ were determined from the SEM images using Kumar's theoretical approximation ${ }^{42}$ according to Eqns (3) and (4), where $n$ is the number of cells in the image and $A$ is the area of the image. For the determination of these parameters, all the cells in a given area were taken into consideration, both microcellular and nanocellular, so the cell density was measured in the same way for the systems with and without sepiolites.

$$
\begin{gathered}
N_{\mathrm{v}}=\left[\frac{n}{A}\right]^{3 / 2} \\
N_{0}=\frac{N_{\mathrm{v}}}{\rho_{\mathrm{r}}}
\end{gathered}
$$

The software measures the dimensions of each cell in four directions and then it calculates the cell size of each cell by averaging the values obtained in the four directions. Once all the cells are measured, the software provides the distribution of 
the cell size, from which the average cell size $(\phi)$ of the sample and the standard deviation of the cell size distribution, $S D$, are calculated. Note that the two-dimensional cell size values were always corrected to obtain the correct three-dimensional value by multiplying by $1.273 .{ }^{41}$ For the microcellular materials (without sepiolites), all the cells were considered to calculate the average cell size $\phi$ and SD. For the materials with sepiolites, in which there is a bimodal structure, only the nanometric cells were counted for determining these parameters $(\phi, S D$ and $\mathrm{SD} / \phi)$. The motivation underlying this analysis is that the majority of cells are nanometric and the fraction occupied by the micrometric cells is usually small (10\% in volume for some materials). In addition, this work is focused on characterizing the nanocellular structure. In a previous work ${ }^{38}$ we already characterized in detail the two populations of cells in PMMA/sepiolite systems. The cell sizes of all the materials were determined in both the MD and TD planes.

In addition, anisotropic nanocellular structures were observed. To quantify the orientation of the cells, the anisotropy ratio was measured. Once again, for the microcellular materials, all the cells were considered in the analysis, whereas for the bimodal systems with micrometric and nanometric cells only the latter were taken into account. The anisotropy ratio was determined in the two planes explained in Fig. 1(b): in the MD plane, $A_{M D}$ was measured as the ratio between the cell size observed in the extrusion direction and the average cell size measured in a direction perpendicular to the extrusion direction (Eqn (5)), whereas in the TD plane, $A R_{T D}$ was calculated as the ratio between two perpendicular cell sizes (Eqn (6)) (note that because of the symmetry of the cylindrical filaments, there are no well-defined directions in the TD plane). The software provides the distribution of anisotropy ratios, from which the average anisotropy ratios and the standard deviation of the distribution can be calculated.

$$
\begin{aligned}
& \mathrm{AR}_{\mathrm{MD}}=\frac{\phi_{\mathrm{MD}}}{\phi_{\mathrm{TD}}} \\
& \mathrm{AR}_{\mathrm{TD}}=\frac{\phi_{\mathrm{TD}_{1}}}{\phi_{\mathrm{TD}_{2}}}
\end{aligned}
$$

\section{Open cell content}

Open cell content $(\mathrm{OC})$ of the cellular materials was measured according to the ASTM D6226-10 standard using a gas pycnometer (AccuPyc II 1340, Micromeritics). The equation to calculate OC is

$$
\text { OC }(\%)=100 \times \frac{V-V_{p}-V_{s}}{V\left(1-\rho_{r}\right)}
$$

where $V$ is the geometric volume of the sample, $V_{p}$ is the volume measured by the pycnometer and $V_{s}$ is a penalty volume to account for the exposed cells at the surface of the sample. The geometric volume was determined from the cellular material density (measured by the water displacement method) and its mass (measured with an AT261 Mettler-Toledo balance). $V_{p}$ was determined by performing a pressure scan (from 0.02 to $0.13 \mathrm{MPa}$ ) in the gas pycnometer and measuring the pycnometric volume for each pressure. It was assumed that no more gas is able to enter the interconnected open cells when the measured volume remains constant for an increase in pressure. $V_{p}$ was calculated as the average of these last measured constant volume values. Note that, as $V_{s}$ is proportional to the cell size, this value becomes negligible for microcellular and nanocellular materials.

\section{RESULTS AND DISCUSSION}

\section{Orientation of sepiolites in extruded filaments}

In a previous work ${ }^{38}$ we proved that the addition of sepiolites to a PMMA matrix led to both micrometric aggregates and well-dispersed individual sepiolites. In the present work, micrometric aggregates were also detected in the solids containing sepiolites, but it was not possible to detect in the same micrograph both individual particles and aggregates because of their very different scale (nanometric versus micrometric). For the purposes of this work, we will focus our attention on the well-dispersed sepiolites that are, as will be explained later, the final reason for having an anisotropic cellular structure. General SEM images of the nanocomposites and particle aggregates can be found in the supporting information.

Figure 2 shows high-magnification images of the morphology of the solid materials produced in this work in which the individual sepiolites can be detected. The images in the top row correspond to the surface perpendicular to the extrusion direction (TD), whereas the bottom row presents the SEM micrographs taken in the extrusion plane (MD). The well-dispersed individual particles can be observed in the SEM micrographs, and moreover, significant differences are found between the two planes analysed. In the TD plane (Figs 2(a) -(d)), only the upper extreme of the particles can be seen in the images. In contrast, in the MD plane (Figs 2(e)-(h)) the complete needle-like sepiolites are observed, showing that the particles are aligned in the extrusion direction. Then, from the SEM qualitative analysis we conclude that as a result of the extrusion process, the sepiolites are mainly placed along the machine direction.

Table 2 summarizes the quantitative analysis of the density of sepiolites in the two planes considered. Note that the particle density is smaller in the MD plane due to the needle-like shape of the sepiolites. Particle densities exceeding $10^{13}$ particles $\mathrm{cm}^{-3}$ are measured. Regarding the effect of the different types of particles, we observe that the material 1.5\%-S-LQAS shows a smaller particle density than $1.5 \%-\mathrm{S}-\mathrm{HQAS}$, that is, a greater amount of QAS improves the dispersion of the particles. For the systems with greater contents of the sepiolite S-HQAS, a larger number of particles is observed when the content increases. In particular, when the content is as high as $10 \mathrm{wt} \%$ (Fig. 2(h)) a high density of particles is detected (see supporting information for more images of this nanocomposite).

\section{Effect of modification of sepiolites}

Table 3 summarizes the relative density of the cellular materials produced with the pure PMMA and the composites with $1.5 \mathrm{wt} \%$ of different filler types. It is observed that, with the foaming conditions used in this work, the four materials present very similar densities. Then, the addition of $1.5 \mathrm{wt} \%$ of the QAS or the sepiolites S-LQAS and S-HQAS does not affect the ability of the PMMA to expand.

On the other hand, significant variations in the cellular structures are detected in the SEM micrographs (Fig. 3). The pure polymer shows a microcellular structure with cell sizes of a few micrometres. Although the cell size distribution is heterogeneous, similar structures are found in both the TD plane (Fig. 3(a)) and the MD plane (Fig. 3(e)). After the addition of the QAS, the cellular structure varies appreciably (Figs $3(b)$ and (f)). A bimodal structure appears, with the main population of micrometric cells (cells around $3 \mu \mathrm{m}$ ) and sub-micrometric cells (slightly smaller than $1 \mu \mathrm{m}$ ) among them. Then, the addition of the QAS has a strong effect on the cellular structure of PMMA. 


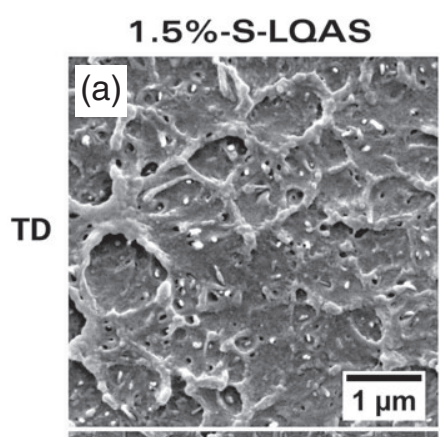

\section{$1.5 \%-S-H Q A S$}
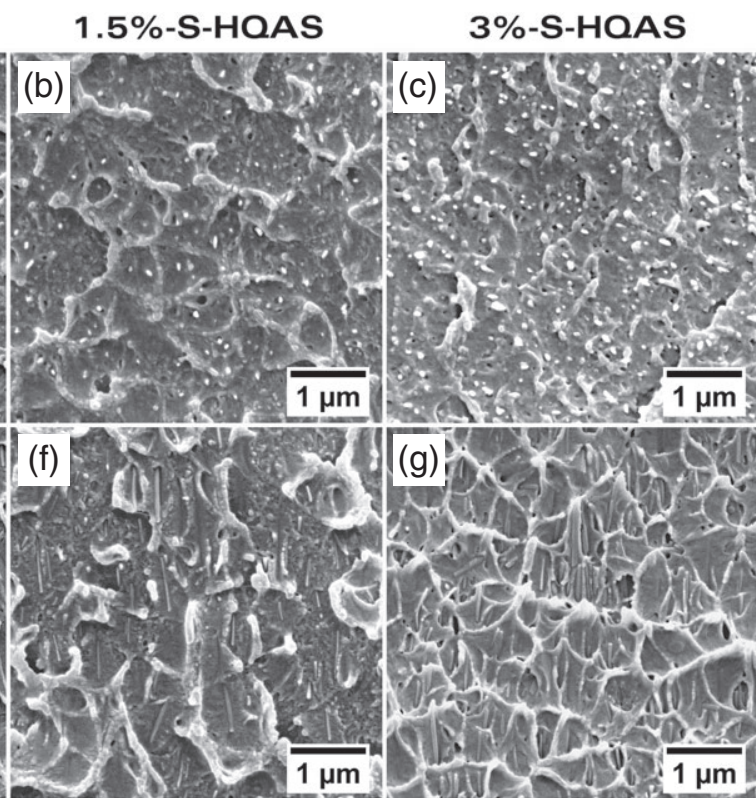

$10 \%-S-H O A S$
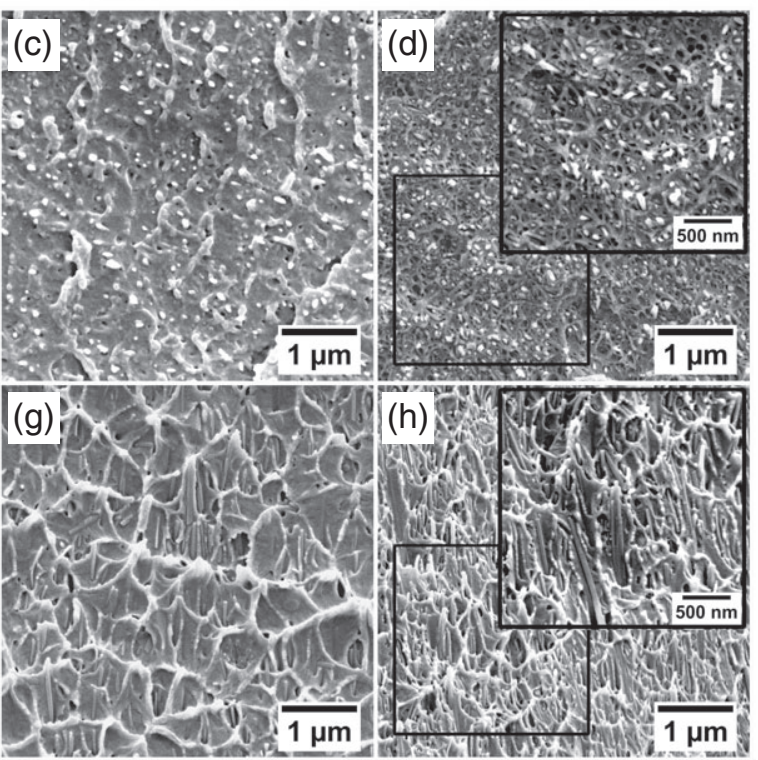

Figure 2. SEM micrographs of solid PMMA/sepiolite nanocomposites: (a, e) 1.5\%-S-LQAS; (b, f) 1.5\%-S-HQAS; (c, g) 3\%-S-HQAS; (d, h) 10\%-S-HQAS. Images in top row show the TD plane and those in bottom row the MD plane.

\begin{tabular}{|lcc|}
\hline $\begin{array}{l}\text { Table 2. Density } \\
\text { nanocomposites }\end{array}$ & of sepiolites in solid & PMMA/sepiolite \\
Material & $\begin{array}{c}\text { Particle } \\
\text { density TD } \\
(\text { particles cm }\end{array}$ & $\begin{array}{c}\text { Particle } \\
\text { density MD }\end{array}$ \\
\hline 1.5\%-S-LQAS & $(1.9 \pm 0.5) \times 10^{13}$ & $(1.1 \pm 0.1) \times 10^{13}$ \\
1.5\%-S-HQAS & $(2.4 \pm 0.3) \times 10^{13}$ & $(1.3 \pm 0.1) \times 10^{13}$ \\
3\%-S-HQAS & $(1.0 \pm 0.2) \times 10^{14}$ & $(1.8 \pm 0.3) \times 10^{13}$ \\
10\%-S-HQAS & $(5.0 \pm 2.0) \times 10^{14}$ & $(9.7 \pm 0.9) \times 10^{13}$ \\
\hline
\end{tabular}

To analyse this effect in detail, the cell size distributions of the PMMA and the material 1.5\%-QAS are displayed in Fig. 4. Figure 4(a) shows that the pure polymer presents a wide but monomodal distribution of the cell size, with an average cell size of around $1.8 \mu \mathrm{m}$ in both TD and MD planes. On the other hand, in Fig. 4(b) the bimodal structure seen in the SEM images can be appreciated, with a sharp peak at around $0.5-1 \mu \mathrm{m}$ and wide peak at around $3 \mu \mathrm{m}$. As a consequence of the larger number of small cells, the average cell size is below micrometric. Once again, the TD and MD planes show very similar distributions. Therefore, it can be concluded that the addition of a QAS induces the appearance of sub-micrometric cells in the PMMA.
In contrast, the addition of sepiolites modified with this salt causes a completely different structure. Figures 3(c) and (g) and Figs $3(\mathrm{~d})$ and (h) show the micrographs of the materials produced with S-LQAS and S-HQAS, respectively. In this case, a bimodal structure is also observed, but with a small fraction of micrometric cells and a predominant population of nanometric cells, as seen in the zoomed images of Figs 3(c) and (g) and Figs 3(d) and (h). We previously reported ${ }^{38}$ that added sepiolites modified with a QAS act as nucleating agents in the gas dissolution foaming of PMMA. It was suggested that the microcellular pores appear due to micrometric sepiolite aggregates, whereas the well-dispersed sepiolites (as shown in Fig. 2) account for the presence of nanocellular pores. For these materials, the volume fraction occupied by the nanometric cells is high: around $80 \%$ for $1.5 \%$-S-LQAS and almost $90 \%$ for $1.5 \%$-S-HQAS (Table 3). If we assume the micrometric pores are due to particle aggregates, we can conclude that the sepiolite S-LQAS was more poorly dispersed than the sepiolite S-HQAS. This is in agreement with the analysis of the solid nanocomposites (Table 2). Then, it is plausible to believe that a higher content of the salt (20.5 wt\% in S-HQAS versus $9.5 \mathrm{wt} \%$ in S-LQAS) enhances the dispersion of the sepiolites.

The cell nucleation density of the four materials of this section is included in Table 3, in both TD and MD planes. The addition of QAS increases the cell nucleation density from $5 \times 10^{11}$ to $4 \times 10^{12}$ nuclei $\mathrm{cm}^{-3}$, that is, almost one order of magnitude. Regarding

\begin{tabular}{|c|c|c|c|c|}
\hline Material & Relative density & $V_{\text {nano }}(\%)$ & $\begin{array}{l}\text { Cell nucleation density } \\
\text { TD (nuclei } \mathrm{cm}^{-3} \text { ) }\end{array}$ & $\begin{array}{l}\text { Cell nucleation density } \\
\text { MD (nuclei } \mathrm{cm}^{-3} \text { ) }\end{array}$ \\
\hline PMMA & $0.30 \pm 0.02$ & 0 & $(4.6 \pm 0.5) \times 10^{11}$ & $(5.5 \pm 0.5) \times 10^{11}$ \\
\hline $1.5 \%-\mathrm{QAS}$ & $0.28 \pm 0.01$ & 0 & $(4.2 \pm 0.4) \times 10^{12}$ & $(4.8 \pm 0.5) \times 10^{12}$ \\
\hline $1.5 \%-S-L Q A S$ & $0.28 \pm 0.01$ & 79 & $(4.7 \pm 0.9) \times 10^{13}$ & $(2.9 \pm 0.3) \times 10^{13}$ \\
\hline $1.5 \%-\mathrm{S}-\mathrm{HQAS}$ & $0.27 \pm 0.01$ & 88 & $(9.3 \pm 0.1) \times 10^{13}$ & $(4.5 \pm 0.1) \times 10^{13}$ \\
\hline
\end{tabular}




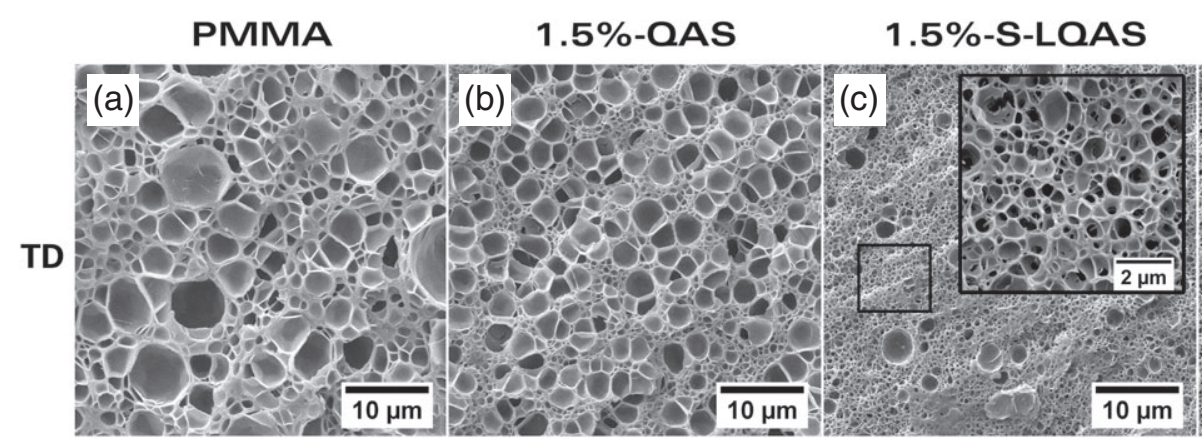

\section{$1.5 \%-S-H Q A S$}
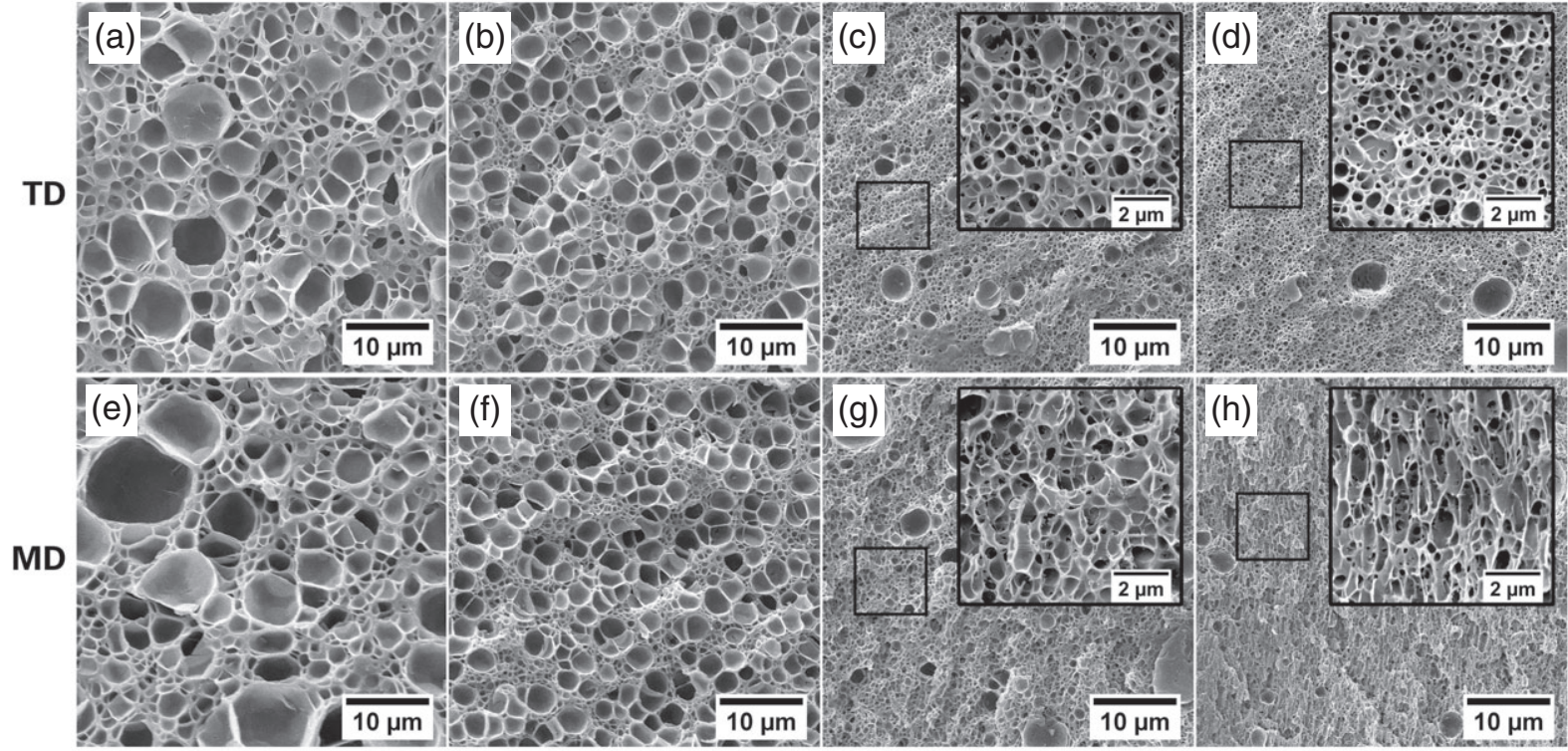

Figure 3. SEM micrographs of cellular materials produced with $1.5 \mathrm{wt} \%$ of different filler types: (a, e) PMMA; (b, f) 1.5\%-QAS; (c, g) 1.5\%-S-LQAS; (d, h) $1.5 \%$-S-HQAS. Images in top row show the TD plane and those in bottom row the MD plane.
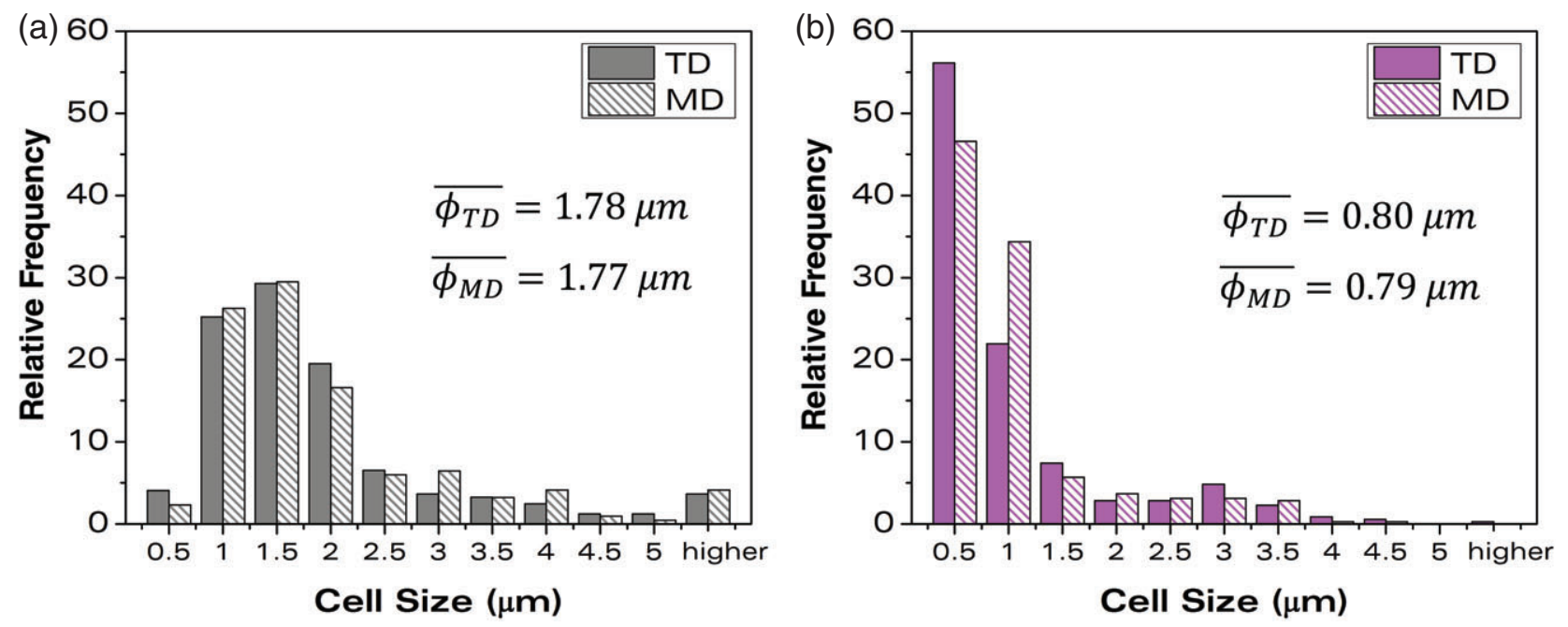

Figure 4. Cell size distributions and average cell sizes measured in TD and MD planes of (a) PMMA and (b) 1.5\%-QAS.

the effect of the sepiolites, they increase the nucleation even more, up to $4.7 \times 10^{13}$ nuclei $\mathrm{cm}^{-3}$ for $1.5 \%$-S-LQAS and almost to $10^{14}$ nuclei $\mathrm{cm}^{-3}$ for $1.5 \%$-S-HQAS in the TD plane. The sepiolite with the greatest amount of QAS has the strongest nucleating effect according to the results of Table 3, also in agreement with the observation of Fig. 3. This result can also be attributed to a worse dispersion of the sepiolites in the nanocomposite $1.5 \%$-S-LQAS. For the same total amount of particles, more particles are aggregated in the material with the sepiolite S-LQAS, resulting in less well-dispersed sepiolites and thus a weaker nucleating effect. The cell nucleation densities reported in Table 3 are of the same order of magnitude as the particle densities estimated in Table 2, supporting that the well-dispersed particles are acting as nucleating sites. Regarding the differences between the two planes, it is observed that for the blends 1.5\%-S-LQAS and $1.5 \%-\mathrm{S}-\mathrm{HQAS}$, the nucleation in the TD plane is greater than that in the MD plane. This is because of the different particle densities in both planes due to the needle-like shape of the sepiolites.

Regarding the effect of the surface modification of the sepiolites on the cell size, Fig. 5 shows the cell size distribution in the nanocellular region for the materials with $1.5 \mathrm{wt} \%$ of S-LQAS and S-HQAS. It is observed that as a consequence of the higher cell nucleation density previously reported, 1.5\%-S-HQAS presents smaller cell sizes than 1.5\%-S-LQAS in the TD plane, 320 versus $390 \mathrm{~nm}$. Moreover, the cell sizes in the MD plane are higher than in the TD plane, especially for the system with S-HQAS. This result implies some anisotropy in the structure that was not detected in the materials without sepiolites.

In fact, the newest and most interesting finding of this work is evident when the structures in the TD plane are compared with those in the MD plane in the materials with sepiolites. In the plane perpendicular to the extrusion direction, spherically shaped cells are detected. Meanwhile, in the MD plane, in which 



Figure 5. Cell size distributions and average cell sizes measured in nanocellular region of TD and MD planes of (a) 1.5\%-S-LQAS and (b) 1.5\%-S-HQAS.

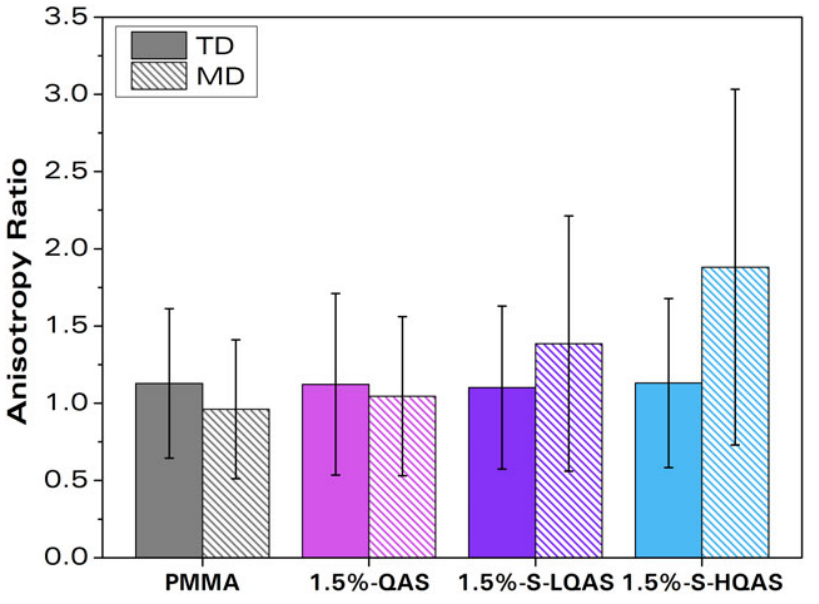

Figure 6. Anisotropy ratio of cellular materials produced with $1.5 \mathrm{wt} \%$ of different filler types measured in TD and MD planes.

the sepiolites were aligned in the extrusion direction in the solids (bottom row of Fig. 2), cells are elongated along the same direction (bottom row of Fig. 3). As a result, anisotropic nanocellular materials are obtained. In contrast, the micrometric cells in these bimodal materials (low-magnification images in Fig. 3) are isotropic. Then, the anisotropy is related to the presence of the well-dispersed sepiolites. Figure 6 shows the anisotropy ratio of the materials analysed in this section. While the pure PMMA and the material with QAS show anisotropy ratios close to one in both planes, nanocomposites with sepiolites present anisotropy ratios greater than one in the MD direction. In particular, the material 1.5\%-S-HQAS presents an average anisotropy ratio as high as 1.88 . The mechanisms underlying this anisotropy are discussed in a later section.

\section{Effect of content of sepiolites}

Table 4 summarizes the relative density of the materials produced with greater contents of the sepiolite S-HQAS. It is observed than when the content is as high as $10 \mathrm{wt} \%$, the expansion capability of the PMMA is reduced and the density of the cellular material is increased. The higher densities measured for the material $10 \%$-S-HQAS could be due to the higher viscosity of the polymer at high particle loads, and also to a decrease of the amount of gas uptake (it has already been found that sepiolites do not absorb $\mathrm{CO}_{2}$ during the gas dissolution foaming process ${ }^{38}$ ).

Figure 7 shows the cellular structure of the materials 3\%-S-HQAS and 10\%-S-HQAS in the TD plane (top row) and in the MD plane (bottom row). The sample with $1.5 \mathrm{wt} \%$ of S-HQAS is also included in Fig. 7 for the sake of comparison. Once again, these materials with sepiolites show a bimodal structure due to the sepiolite aggregates. It is evident from Table 4 that whereas the nanocellular volume fraction in the material with $3 \mathrm{wt} \%$ of S-HQAS is similar to that obtained for $1.5 \mathrm{wt} \%$ of S-HQAS (Table 3), the material with $10 \mathrm{wt} \%$ of particles presents a smaller fraction of nanometric cells. In addition, there are more micrometric cells in this system. We conclude that the addition of $10 \mathrm{wt} \%$ of sepiolites leads to a greater aggregation of the particles, so there are more and larger aggregates, causing more and larger micrometric cells (see SEM images of the nanocomposites in the supporting information). The micrometric cells are isotropic in both planes (Fig. 7). Regarding the nanocellular structure, it is observed that an increase in the sepiolite content leads to a higher cell nucleation density in both planes, the nucleation density being higher in the TD plane (Table 4). This is because there are more well-dispersed nanoparticles as sepiolite content increases (Table 2). As a consequence of the higher nucleation density, the cell size in the nanocellular region decreases as particle content increases (Fig. 8(a)). Cell sizes as low as $150 \mathrm{~nm}$ are obtained in the TD plane for the material with $10 \mathrm{wt} \%$ of particles.

As already seen in the materials with sepiolites of the previous section, the nanocellular structure is isotropic in the TD plane and anisotropic in the MD plane (Figs 7 and 8). This leads to higher average cell size in the MD plane compared to that measured in the TD plane (Fig. 8(a)). It is observed that as particle content increases, the anisotropy ratio slightly increases, from 1.88 at a particle content of $1.5 \mathrm{wt} \%$ to 2.15 when the sepiolite content is $10 \mathrm{wt} \%$. In addition, the width of the distribution of the anisotropy of the cells (given by the error bar in Fig. 8(b)) also increases as particle content does, meaning that more cells are anisotropic for higher particle contents. The anisotropy ratio distributions of these three materials are shown in Fig. 9, supporting these results. As particle content increases, the distribution of anisotropy of the cells becomes wider. The mechanisms underlying the anisotropy appearance and its dependence on the type of sepiolite and its content are discussed in the next section. 
Table 4. Relative density, volume fraction of nanometric cells and cell nucleation density of cellular materials produced with different contents of S-HQAS

\begin{tabular}{lcccc} 
Material & Relative density & $V_{\text {nano }}(\%)$ & $\begin{array}{c}\text { Cell nucleation density } \\
\left.\text { TD (nuclei cm }{ }^{-3}\right)\end{array}$ & $\begin{array}{c}\text { Cell nucleation density } \\
\text { MD }\left(\text { nuclei } \mathrm{cm}^{-3}\right)\end{array}$ \\
\hline 3\%-S-HQAS & $0.29 \pm 0.01$ & 87 & $(1.1 \pm 0.5) \times 10^{14}$ & $(4.5 \pm 0.1) \times 10^{13}$ \\
10\%-S-HQAS & $0.40 \pm 0.02$ & 66 & $(1.4 \pm 0.8) \times 10^{14}$ & $(4.6 \pm 0.2) \times 10^{13}$ \\
\hline
\end{tabular}
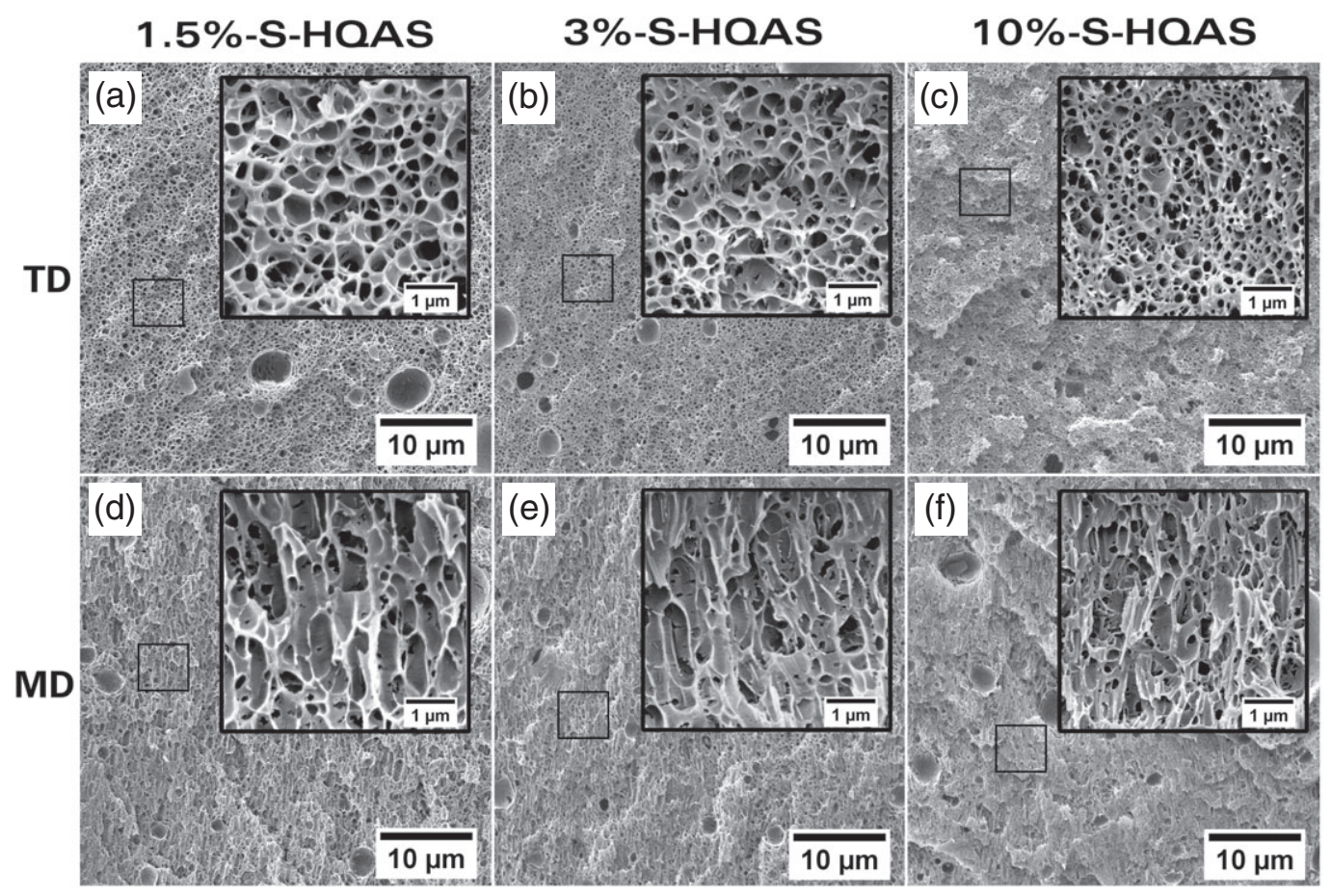

Figure 7. SEM micrographs of cellular materials produced with various contents of S-HQAS: (a, d) 1.5\%-S-HQAS; (b, e) 3\%-S-HQAS; (c, f) 10\%-S-HQAS. Images in top row show the TD plane and those in bottom row the MD plane.

\section{Discussion: mechanisms of anisotropy formation}

Several works ${ }^{27-30,43}$ claim that anisotropic cellular structures can be a result of a preferable growth of the cells in a certain direction. To evaluate if this was the reason underlying the anisotropy observed in the materials of the present work, the expansion ratios in different directions of the cellular materials were measured. The expansion ratio in the $\mathrm{TD}$ direction, $\mathrm{ER}_{\mathrm{TD}}$, was calculated as the ratio between the final diameter of the cellular material and the initial diameter of the solid precursor, whereas the expansion ratio in the $\mathrm{MD}$ plane, $\mathrm{ER}_{\mathrm{MD}}$, was determined as the ratio between the final and the initial lengths. Table 5 summarizes the expansion ratios of all the materials produced in this work in both directions. For all the materials, most of the expansion occurs in the TD plane, that is, in the direction perpendicular to the extrusion direction and opposite to the anisotropy observed. This effect occurs for all materials regardless of the filler type and content, so it is an effect related to the morphology of the polymer matrix. During the extrusion process the polymer is stretched in the extrusion direction, and thus internal tensions (molecular orientation in the extrusion direction) must remain within the solid samples. Then, when the polymer has enough mobility during the foaming process, the tendency is to relax those tensions by growing in the radial direction. The results of Table 5 indicate that the growth direction is not the mechanism of anisotropy formation. In fact, the samples without sepiolites (PMMA and 1.5\%-QAS) presented an anisotropy ratio slightly smaller than 1 in the MD direction (Fig. 6), supporting that the cell growth takes place mostly in the TD direction.

The mechanism we propose to explain the anisotropy is related to a particular effect of the presence of the sepiolites during the growth of the cells. We have observed that the individual sepiolites are in the middle of the cells, both particle and cell elongated in the same direction (Fig. 10). So one possible rationale to explain the anisotropy might be that the cells grow around the sepiolite, which has an elongated shape, and thus the cells are anisotropic. On the other hand, it is also observed that some sepiolites appear between two cells that have been joined to one (red arrows in Fig. 10). Then, sepiolites could be acting as weak points for cell wall rupture, causing coalescence in the direction of the sepiolite, and then provoking the resultant cells to be anisotropic. This mechanism is schematically explained in Fig. 11.

To further investigate this hypothesis, the open cell content was measured and plotted against the anisotropy ratio (Fig. 12(a)). It is observed that a higher open cell content is measured in the samples with S-HQAS, those that presented higher anisotropy ratios. In fact, the materials with more particles, 3 and $10 \mathrm{wt} \%$, show open cell contents of $100 \%$, that is, a completely open structure. These results support the idea that some cell wall rupture is taking place in these systems. 

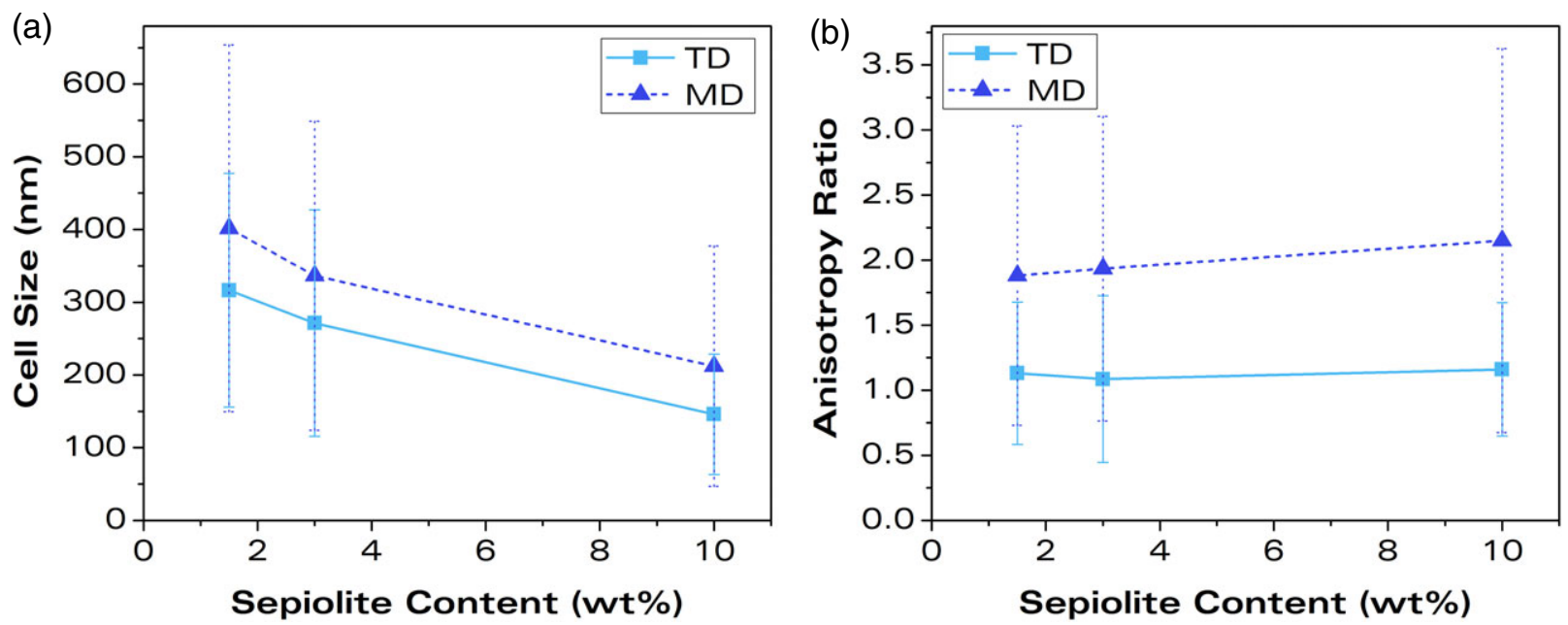

Figure 8. (a) Average cell size and (b) anisotropy ratio measured in nanocellular region of TD and MD planes of cellular materials produced with various contents of S-HQAS.

(a)

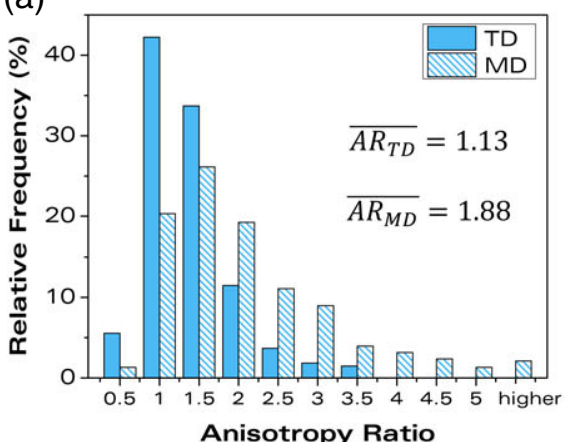

(b)

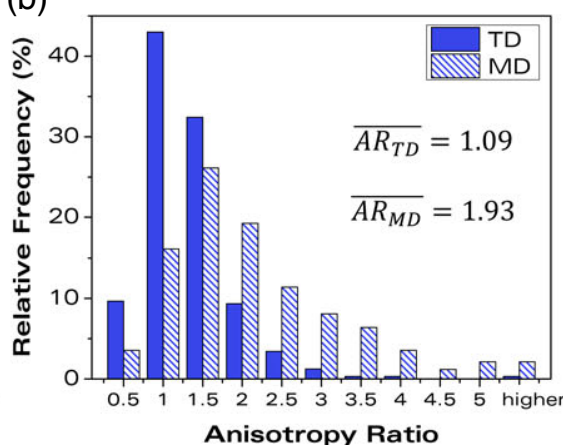

(c)

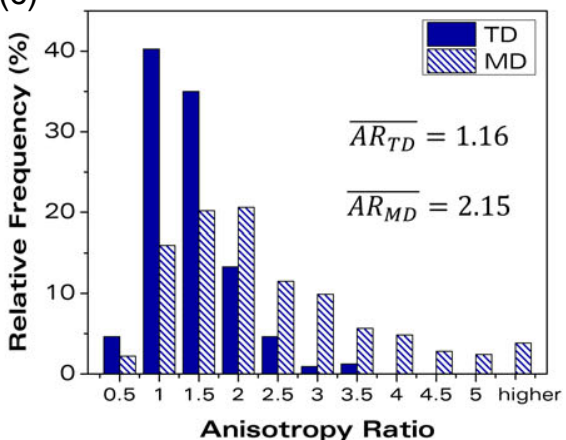

Figure 9. Anisotropy ratio distributions and average anisotropy measured in nanocellular region of TD and MD planes of cellular materials produced with various contents of S-HQAS: (a) 1.5\%-S-HQAS; (b) 3\%-S-HQAS; (c) 10\%-S-HQAS.

\begin{tabular}{|lcc|}
\hline $\begin{array}{l}\text { Table 5. Expansion ratio in TD and the MD directions for all cellular } \\
\text { materials produced }\end{array}$ & ER $_{\mathrm{MD}}$ \\
\hline Material ID & $\mathrm{ER}_{\mathrm{TD}}$ & 1.43 \\
\hline PMMA & 1.58 & 1.44 \\
1.5\%-QAS & 1.64 & 1.44 \\
1.5\%-S-LQAS & 1.66 & 1.46 \\
1.5\%-S-HQAS & 1.65 & 1.37 \\
3\%-S-HQAS & 1.64 & 1.11 \\
10\%-S-HQAS & 1.53 & \\
\hline
\end{tabular}

The different anisotropy ratios found in the materials of this work can then be correlated with the number of well-dispersed sepiolites in each material. As the number of sepiolites increases, the distance between particles decreases, and then it is more likely that two or more sepiolites are aligned and a very anisotropic cell is formed around them. The number of sepiolites is somehow related to the cell nucleation density (assuming one particle produces one cell). Then, the cell nucleation density has been plotted as a function of the anisotropy ratio (Fig. 12(b)), showing this idea that a greater number of particles (higher nucleation densities) yields a greater anisotropy ratio. Therefore, controlling the number and dispersion of sepiolites is a tool for controlling the anisotropy ratio in these systems.

\section{CONCLUSIONS}

Anisotropic nanocellular polymers based on PMMA with needle-like sepiolites have been produced using a two-step gas dissolution foaming method. Anisotropy ratios from 1.38 to as high as 2.15 are obtained as a result of the addition of the nanoparticles.

Solid materials were produced using a twin-screw extruder, and the filaments from the extrusion were used as precursors for the solid-state foaming process. The morphology of the solid samples reveals that the extrusion process aligns the sepiolites in the extrusion direction.

Results show that the addition of $1.5 \mathrm{wt} \%$ of a QAS has an effect on the cellular structure of microcellular PMMA, leading to an increase of the nucleation density of one order of magnitude and a slight reduction of the average cell size. On the other hand, the addition of the same content of sepiolites modified with this salt is even more significant, increasing the nucleation density above the $10^{13}$ nuclei $\mathrm{cm}^{-3}$ and leading to the appearance of a bimodal structure with a predominance of nanometric pores. In particular, between the two sepiolites used in this work, that with the greatest amount of QAS has the strongest nucleating effect, due to a better dispersion of the particles in the solid material. In addition, it is observed that whereas the pure PMMA and the blend with QAS are isotropic, the cellular nanocomposites with sepiolites are highly anisotropic in the plane parallel to the 

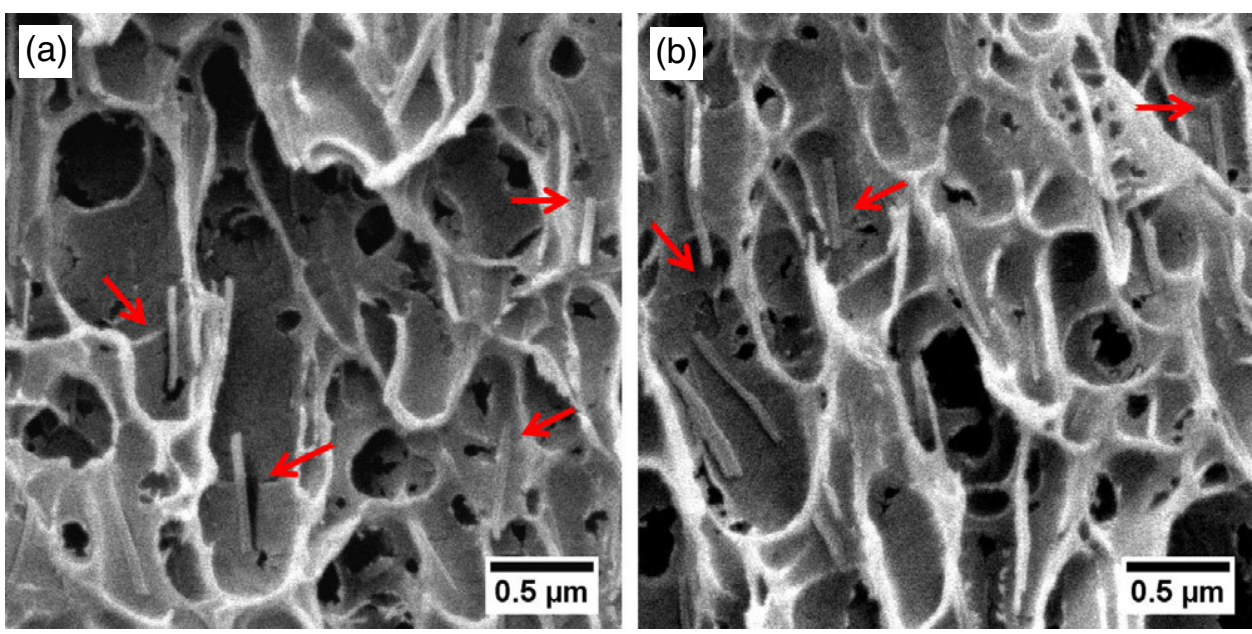

Figure 10. Examples of SEM micrographs of MD plane of sample 3\%-S-HQAS, showing in detail the sepiolites in the cells.

(a)

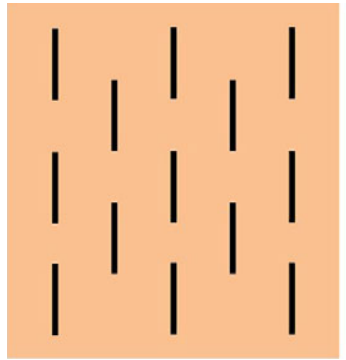

(b)

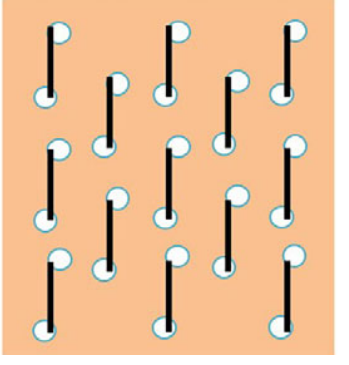

(c)

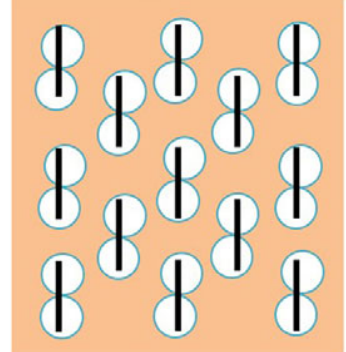

(d)

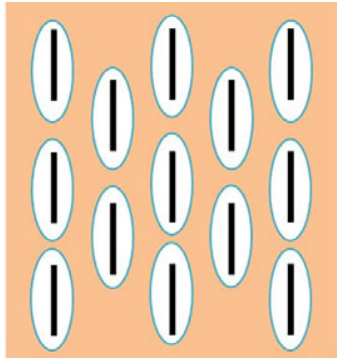

Figure 11. Scheme of the mechanism of anisotropy formation during foaming process: (a) solid material with sepiolites; (b) nucleation on edges of sepiolites; (c) growth of cells; (d) coalescence in sepiolites and appearance of anisotropy.

extrusion direction (and isotropic in the transverse plane). Moreover, increasing the sepiolite content from 1.5 to 3 and $10 \mathrm{wt} \%$ increases even more the anisotropy observed in these materials, at the same time as the nucleation density increases and the cell size decreases.

After analysing the expansion ratio of the materials, it is concluded that the anisotropy is not a consequence of a preferable expansion during the growth of the cells. Instead, a mechanism based on cell coalescence is proposed as being responsible for the formation of anisotropic cells. The needle-like particles act as most likely spots for cell wall rupture, and as they are aligned in the machine direction, cells break and join in that direction, causing an overall anisotropic structure. This hypothesis is supported by open cell measurements. Also, the different anisotropy ratios found in the various nanocomposites can be correlated with the density of well-dispersed sepiolites. (a)

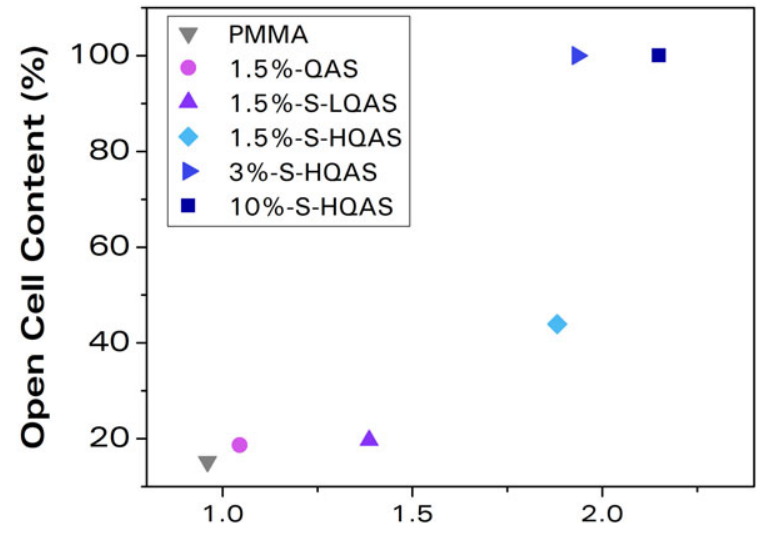

Anisotropy Ratio (b)

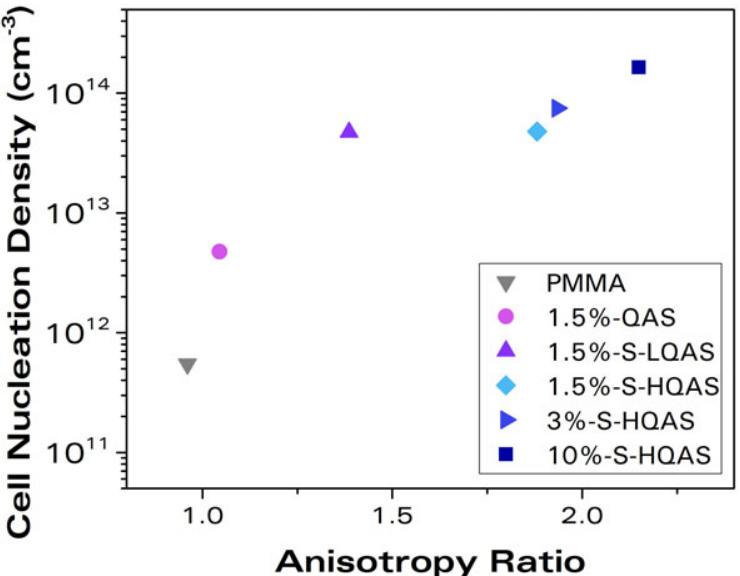

Figure 12. (a) Open cell content and (b) cell nucleation density in MD plane as a function of anisotropy ratio in the MD plane for all materials produced in this work. 


\section{ACKNOWLEDGEMENTS}

Financial support from FPU grant FPU14/02050 (VB) from the Spanish Ministry of Education and a Junta of Castile and Leon grant $(\mathrm{JM}-\mathrm{dL})$ is gratefully acknowledged. Financial assistance from MINECO, FEDER, UE (MAT2015-69234-R) and the Junta de Castile and Leon (VA275P18) is gratefully acknowledged. We also thank Tolsa (Madrid, Spain) for supplying the sepiolites used in this study.

\section{SUPPORTING INFORMATION}

Supporting information may be found in the online version of this article.

\section{REFERENCES}

1 Eaves D, Handbook of Polymer Foams. Rapra Technology Ltd, Shrewsbury (2004).

2 Marketsandmarkets.com Available: http://www.marketsandmarkets .com/Market-Reports/foams-market-1011.html.

3 Costeux S, J Appl Polym Sci 131:41293 (2014).

4 Yokoyama H, Li L, Nemoto T and Sugiyama K, Adv Mater 16:1542-1546 (2004).

5 Guo H, Nicolae A and Kumar V, Polymer (Guildf) 70:231 (2015).

6 Notario B, Pinto J and Rodriguez-Perez MA, Prog Polym Sci 93:78-79 (2016).

7 Miller D and Kumar V, Polymer (Guildf) 52:2910 (2011).

8 Notario B, Pinto J, Solorzano E, de Saja JA, Dumon M and Rodriguez-Perez MA, Polymer (Guildf) 56:57-67 (2015).

9 Wang G, Wang C, Zhao J, Wang G, Park CB and Zhao G, Nanoscale 9:5996-6009 (2017).

10 Liu S, Duvigneau J and Vancso GJ, Eur Polym J 65:33-45 (2015).

11 Forest C, Chaumont P, Cassagnau P, Swoboda B and Sonntag P, Prog Polym Sci 41:122-145 (2015).

12 Wang G, Zhao J, Mark LH, Wang G, Yu K, Wang C et al., Chem Eng J 325:632-646 (2017).

13 Perez-Tamarit S, Notario B, Solorzano E and Rodriguez-Perez MA, Mater Lett 210:39 (2017).

14 Martin-de Leon J, Bernardo V and Rodriguez-Perez MA, Macromol Mater Eng 302:1700343 (2017).

15 Notario B, Pinto J, Verdejo R and Rodrıguez-Pérez MA, Polymer (Guildf) 107:302 (2016).

16 Pinto J, Notario B, Verdejo R, Dumon M, Costeux S and Rodriguez-perez MA, Polymer (Guildf) 113:27 (2017).

17 Notario B, Pinto J and Rodríguez-Perez MA, Polymer (Guildf) 63:116 (2015).
18 Notario B, Ballesteros A, Pinto J and Rodriguez-Perez MA, Mater Lett 168:76-79 (2016)

19 Gibson LJ and Ashby M, Cellular Solids: Structure and Properties, 2nd edn. Cambridge University Press, Cambridge (1997).

20 Huber AT and Gibson LJ, J Mater Sci 23:3031 - 3040 (1988).

21 Andersons J, Kirpluks M, Stiebra L and Cabulis U, Mater Design 92:836-845 (2016).

22 Martinez-Diez JA, Rodrıguez-Perez MA, de Saja JA, Arcos y Rabago LO and Almanza OA, J Cell Plast 37:21 (2001).

23 Rodríguez-Pérez MA, Alonso O, Souto J and de Saja JA, Polym Test 16:287-298 (1997).

24 Antunes M, Realinho V, Velasco Jl, Solórzano E, Rodríguez-Pérez MÁ and De Saja JA, Mater Chem Phys 136:268-276 (2012).

25 Wicklein B, Kocjan A, Salazar-Alvarez G, Carosio F, Camino G, Antonietti M et al., Nat Nanotechnol 10:277 (2014).

26 Killeen D, Frydrych M and Chen B, Mater Sci Eng C 32:749-757 (2012).

27 Laguna-Gutierrez $E$, Van Hooghten R, Moldenaers $\mathrm{P}$ and Rodriguez-Perez MA, J Appl Polym Sci 132:42430 (2015).

28 Arora KA, Lesser AJ and McCarthy TJ, Macromolecules 38:446 (1997).

29 Oliveira-Salmazo L, Lopez-Gil A, Silva-Bellucci F, Job AE and Rodriguez-Perez MA, Ind Crops Prod 80:26-35 (2016).

30 Bernardo V, Laguna-gutierrez E, Lopez-gil A and Rodriguez-perez MA, Mater Design 114:83 (2016).

31 Alvarez A, Santaren J, Esteban-Cubillo A and Aparicio P, in Development in Palygorskite-Sepiolite Research, ed. by Galan E and Singer A. Elsevier, Oxford (2011).

32 Ruiz-Hitzky E, J Mater Chem 11:86-91 (2001).

33 Santaren J, Alvarez A, Esteban-Cubillo A, Notario B, Velasco D and Rodrıguez-Perez MA, Foams 2012. SPE (society of plastics engineers), US, p. 1 (2012).

34 García N, Guzman J, Benito E, Esteban-Cubillo A, Aguilar E, Santaren J et al., Langmuir 27:3952-3959 (2011).

35 Shahi P, Behravesh AH, Rasel S, Rizvi G and Pop-lliev R, Cell Polym 36:221-250 (2017).

36 Ludwiczak J, Frackowiak S and Łuzny R, Cell Polym 37:69-79 (2018).

37 Kumar V and Suh NP, Polym Eng Sci 30:1323-1329 (1990).

38 Bernardo V, Martin-de León J, Laguna-Gutiérrez E and Rodríguez-Pérez MÁ, Eur Polym J 96:10-26 (2017).

39 Mandarim-de-Lacerda CAA, Brazilian Acad Sci 75:469-486 (2003).

40 Hilyard NC and Cunningham A, Low Density Cellular Plastics: Physical Basis of Behaviour. Chapman and Hall, London (1994).

41 Pinto J, Solorzano E, Rodriguez-perez MA and De Saja JA, J Cell Plast 49:555-575 (2013).

42 Kumar V, Process synthesis for manufacturing microcellular thermoplastic parts. PhD. Thesis, Massachusetts Institute of Technology, Cambridge, MA (1988).

43 Singh I, Gandhi A, Biswal M, Mohanty S and Nayak SK, Cell Polym 37:121 - 149 (2018). 